\title{
Entrevista: Pierre Trinquet e o ponto de vista da atividade em formação profissional e segurança no trabalho
}

\author{
Maria Elisa Siqueira Borges ${ }^{1}$ e Paulo César Zambroni-de-Souza ${ }^{2}$
}

Em visita ao Brasil, o sociólogo francês Pierre Trinquet concedeu entrevista aos Cadernos de Psicologia Social do Trabalho, conduzida por Maria Elisa Siqueira Borges e Paulo César Zambroni-de-Souza. Em sua fala, o sociólogo professor da Université de la Méditerranée e da Université de Provence - passeia pelos temas da atividade, trabalho, prevenção dos riscos no trabalho, formação profissional, grupos de encontro sobre o trabalho, gestão, sempre na perspectiva da Ergologia, que visa compreender e transformar positivamente o trabalho, considerando sempre o ponto de vista de quem está na atividade e que tem seu principal polo de desenvolvimento o Departamento de Ergologia - Análise Pluridisciplinar de Situações de Trabalho, Université de Provence, França.

Cadernos - Professor Pierre Trinquet, para apresentá-lo aos leitores dos Cadernos de Psicologia Social do Trabalho, fale-nos de sua formação e experiência profissional e acadêmica.

Pierre Trinquet - Eu havia deixado a escola aos 17 anos de idade, com um simples diploma técnico e graças à Formação Profissional Contínua (FPC) pude chegar até o doutorado em Sociologia na Universidade de Provença, França, e chegar a professor/pesquisador na universidade. Fui sindicalista durante muitos anos, secretário do comitê $\hat{e}^{3}$ de uma grande empresa de construção civil do sudoeste da França e também secretário da comissão de formação. Eu sou, há mais de vinte anos, administrador e, durante quatro anos, presidente de um organismo que gere paritariamente todos os fundos da FPC da construção civil do sudoeste da França. É o organismo de maior importância da FPC dessa zona geográfica, pois a indústria civil dessa região é a primeira indústria tanto em número de empregados, como em orçamento. Bem, evidentemente, eu não poderia analisar toda essa experiência, diversa e acumulada, senão com um olhar, um posicionamento de um ergólogo, que sou há 22 anos, depois de todo começo desta aventura intelectual e universitária. Então, esta tem sido verdadeiramente uma aventura e ela está longe de estar terminada.

Cadernos - O que é a Formação Profissional Contínua?

Pierre Trinquet - É um direito do trabalho, importante sobre o plano social e, sobretudo, econômico e político na França, que assegura:

- formação, para todos os assalariados, durante as horas de trabalho e remuneradas, sem ruptura do contrato de trabalho. Essas formações podem ter a duração de alguns dias ou um ano. Elas podem se renovar, pelo menos, a cada três anos;

- a formação pode ocorrer por proposição patronal ou do assalariado. $O$ empregador não pode recusar uma formação, salvo em casos muito precisos e previstos por lei;

- uma parte importante do financiamento é assegurado pelas empresas. Nas grandes empresas, a cotização real se situa, em média, em torno de $3 \%$. O que mostra bem o interesse que o patronato atribui à FPC.

1 Doutora em Psicologia Social, professora universitária e sócia da Diálogos - Consultoria em Gestão com Pessoas.

2 Docente do Departamento de Psicologia e do Mestrado em Psicologia Social da Universidade Federal da Paraíba.

3 Obrigatório na legislação trabalhista francesa para empresas com mais de 50 empregados, o Comitê de Higiene, Segurança e Condições de Trabalho (CHSCT) é uma comissão que agrupa representantes da empresa e dos trabalhadores para tratar de assuntos de diversas naturezas ligados aos interesses dos trabalhadores. 
Aqui, alguns números para situar essa questão: em 2004, 24 bilhões de euros foram consagrados à FPC e à formação profissional em geral, dos quais 10 bilhões de euros foram liberados pelas empresas para seus assalariados; 14 bilhões de euros liberados pelo Estado, pelas administrações e coletividades locais, dos quais 8 bilhões de euros foram consagrados à formação para pessoas desempregadas. Esses números servem para pagar os custos pedagógicos, os salários e as despesas de funcionamento.

A gestão da FPC, tanto financeira quanto política, é assegurada paritariamente (sindicatos de patrões e de assalariados). $\mathrm{O}$ Estado não se outorga senão um direito de olhar a posteriori, para verificar e validar o que se fez.

Esse foi incontestavelmente um grande avanço socioeconômico. A FPC permitiu uma adaptação da mão de obra aos problemas estruturais, tecnológicos e sociológicos, além de societais. Ofícios desapareceram, outros apareceram, com técnicas, tecnologias, normas novas, em particular com a informatização da produção e dos serviços. Isso foi um grande transtorno. A FPC contribuiu, grandemente, para que tudo isso se passasse sem desgastes nem revoltas em excesso. Podemos dizer que todo mundo ganhou alguma coisa: os assalariados, o patronato e os políticos. Mas, em minha experiência, tanto como beneficiário, quanto como ergólogo, e sobretudo enquanto sindicalista no seio dessa estrutura, vejo algumas fraquezas.

Cadernos - Quais seriam estas fraquezas?

Pierre Trinquet - Eu penso que seriam, pelo menos, três: o paritarismo e o a presença abusiva do patronato; a confusão emprego e trabalho e suas consequências; a forma e os conteúdos inadaptados aos trabalhadores.

O paritarismo significa que em todas as instâncias, uma metade dos membros é designada pelas organizações patronais concernidas; a outra metade, com a mesma quantidade, por cada uma das cinco organizações sindicais representativas francesas.

Teoricamente, esse tipo de funcionamento pode parecer sedutor, mas a realidade é bem diferente. $\mathrm{O}$ resultado constatado é um desequilíbrio patente entre a metade patronal que se apresenta em todos os níveis estruturais unida, motivada e competente (eles têm os meios para isso) e a outra metade sindical, desunida, frequentemente em concorrência e desmotivada pela ineficácia constatada de suas ações.

Com relação à confusão emprego e trabalho, diante dos transtornos evocados há pouco, surgiu, rapidamente, no meio político a necessidade de realizar um "acompanhamento social" de todos os transtornos previsíveis ou em curso. E isso por prudência, para evitar uma explosão social, além de uma revolução. Esse acompanhamento social se desenvolveu a partir da década de 1970, e é um dos papéis essenciais que foi destinado à FPC.

Vemos, pois, que desde o começo, o laço entre formação e emprego foi estabelecido. Esse caráter primário da relação formação/emprego ocultou um pouco as lógicas entre formação e trabalho, a ponto de, frequentemente, inclusive em textos oficiais, esses dois conceitos, trabalho e emprego, serem confundidos.

O conceito de emprego reenvia a um contrato: contrato de duração determinada ou contrato de duração indeterminada, temporários, precários, jovens-empregos etc. O que não prejulga a atividade a executar. Ao se polarizar demais sobre o emprego - além da empregabilidade, para responder às necessidades sociais evidentes -, terminou-se por perder de vista que a formação deve ser concebida, organizada e gerida para responder às necessidades da atividade e não da natureza do contrato de trabalho.

Ora, o que mobiliza os deliberadores políticos é "dar trabalho" ao maior número de pessoas, ou seja, um emprego. Toda energia dispensada tende para esse objetivo. A atividade torna-se secundária e negligenciada por eles. E todas as decisões e textos oficiais falam de emprego, mesmo quando eles escrevem "trabalho". Há confusão entre esses dois conceitos, certamente vizinhos, mas que enviam a realidades muito diferentes. Com a Ergologia, sabe-se bem de todas as derivações que isso gera e a experiência mostrou que, infelizmente, foi o que se passou: em função de se preocupar demais com o emprego, negligenciou-se o trabalho. Por esse fato, a FPC na França pouco se interessou pelas evoluções das atividades de trabalho e as formações propostas essencialmente não respondem às necessidades geradas por essas evoluções. Grave lacuna, não?

A terceira fraqueza, sempre segundo meu ponto de vista, que concerne à FPC francesa, reenvia aos aspectos pedagógicos e organizacionais. Quando, no começo dos anos 70, colocou-se para funcionar essa instituição nacional, no plano pedagógico a inspiração se deu a partir do único modelo que tínhamos à 
mão, ou seja, aquele da educação nacional. Desde o começo, as formações são realizadas, "naturalmente", a partir deste único modelo disponível.

Pessoalmente, não tenho nada contra o modelo escolar, que, além do mais, fez suas provas e eu não me permitirei, aqui, criticar. Eu simplesmente destacarei que, ao copiá-lo, não se deram conta de que não se endereçam ao mesmo público. Que não se pode fazer a mesma coisa (ou quase) quando se dirige a um público, sobretudo de jovens e em formação inicial, que tem praticamente tudo a aprender e quando se endereça a trabalhadores adultos, que já possuem um "saber investido" ${ }^{4}$ e mais particularmente nos domínios nos quais desejam se formar, se aperfeiçoar. Juntemos a isso que frequentemente os trabalhadores guardam más lembranças de seus percursos escolares. Isso parece ser um problema a resolver. É necessário inventar, experimentar outros modelos pedagógicos, vislumbrar outras configurações, além de outros laços de formação que os laços tradicionais e habituais. No Departamento de Ergologia, temos algumas ideias a esse respeito. Juntamente com Louis Durrive nós chamamos essa nova maneira de conceber a formação dos trabalhadores de ergoformação.

Cadernos - Do que se trata, quando se fala em ergoformação?

Pierre Trinquet - Para entender o conceito de ergoformação, é necessário compreender o que a Ergologia entende por trabalho. Trata-se de uma questão à qual é impossível responder com precisão, pois o trabalho, enquanto atividade humana, é alguma coisa complexa. Pessoalmente, eu entendo que o trabalho é colocar em ato a atividade humana, que engloba e restitui toda a complexidade humana. E Deus sabe que a complexidade humana é vasta!

Entretanto, a grande maioria das pessoas - incluindo os próprios assalariados -, está convencida que o trabalho é alguma coisa simples. Disso deriva a maior parte de nossas dificuldades de compreender, conhecer, formar e gerenciar a atividade laboriosa. Essa simplificação geral vem, dentre outras coisas, da confusão entre trabalho e atividade.

A atividade deve ser tomada no sentido de atividade interior. É o que se passa na cabeça e no corpo da pessoa no trabalho, em diálogo com seu meio e os outros. É invisível, mas muito fecunda e eficaz. É isso que faz com que, definitivamente, o trabalho possa se realizar e se realiza.

Como regra geral, há um interesse pelo trabalho, mas não pela atividade. Entretanto, não são a mesma coisa. Quando pedimos a um assalariado para nos explicar o que ele faz, ele descreve sempre seu trabalho, jamais descreve espontaneamente sua atividade. É preciso muita perseverança, convicção, depositar confiança, para ele conseguir falar de sua atividade. Ou seja, espontaneamente o assalariado nos fala de suas tarefas, de seu posto de trabalho, do resultado - material ou imaterial - que é esperado, dos procedimentos que ele deve seguir e executar, dos materiais de que se utiliza etc. E isso não lhe coloca nenhum problema, porque ele não é implicado pessoalmente. Para ser breve, ele nos descreve seu trabalho prescrito, para ele seu trabalho é isso e nada mais, entretanto...

Cadernos - Isso remete à distinção entre o trabalho prescrito e o trabalho real.

Pierre Trinquet - Certamente! Há quase 60 anos os ergonomistas de língua francesa, sob a direção do professor Alain Wisner, descobriram - observando postos de trabalho extremamente taylorizados - que havia sempre uma distância entre o trabalho tal qual ele foi prescrito e o modo pelo qual ele era, em definitivo, realizado.

Há quase 60 anos eles lançaram sua famosa "batalha do trabalho real". Batalha exclusivamente intelectual e universitária, para fazer, por fim, admitir a distância prescrito/real. Eu acredito que essa batalha de convicção foi ganha. Não há mais muita gente para negar essa distância (mesmo que ainda haja quem sonhe suprimi-la), porque é contra a natureza do próprio conceito.

Essa distância sempre existiu, desde o início da hominização, desde a aparição do homo faber. As transgressões que surgem dali explicam, em boa parte, a evolução constante da atividade humana. Senão, nós estaríamos no mesmo estágio das formigas e das abelhas. Ou seja, nós faríamos coisas certamente admiráveis, mas sempre idênticas. Ora, esse não é o caso. O trabalho humano está em constante evolução e sobre todos os planos ao redor do mundo. Mais ou menos rapidamente e profundamente, segundo a civilização, mas não é jamais estático no tempo.

E nós sabemos que isso corresponde a uma capacidade especificamente humana, que Yves Schwartz que é o principal representante da perspectiva ergológica - chama "uso de si" e que outros chamam

4 Pierre Trinquet explicita adiante o que é saber investido. 
"auto-organização". Essa capacidade, que apenas os humanos possuem e que lhes permite "se usar" deles mesmos como eles bem entendem. É uma liberdade, muito limitada por exigências incontornáveis - que todo mundo percebe bem -, mas não há jamais apenas uma "boa maneira" de fazer as coisas. Há sempre escolhas, ínfimas que sejam. É isso que diferencia os seres humanos dos robôs, que fazem sempre a mesma coisa, a partir da maneira como foram programados. Um robô não tem alma, enquanto que o humano hesita sempre, porque ele é consciente e pode escolher, adaptar-se.

Essa particularidade do ser humano está no coração de um conceito ontológico e antropológico maior, mesmo que ele não seja ainda levado muito a sério pela comunidade científica. Mas esta não é a primeira vez, na história das ciências, que isso ocorre. Isso quer dizer, sem rodeios: que a evolução do trabalho depois da noite dos tempos, explica, por uma parte, a evolução do Homem e que a evolução do Homem explica a evolução de sua atividade laboriosa. Que há uma dialética entre essas duas evoluções, e essa dialética é um dos principais motores da evolução humana. E isso é, então, um conceito ontológico e antropológico.

Cadernos - Voltando, então, ao conceito de ergoformação, do que se trata?

Pierre Trinquet - Não se trata somente das ideias, mas também das práticas. Por exemplo (mas não é só isso), buscamos nos inspirar e adaptar o dispositivo concebido por nós, os "grupos de encontros de trabalho". É isso que, pessoalmente, eu me esforço para praticar quando eu intervenho na empresa. No começo, eu anuncio que sei coisas que eles não sabem, mas que eu sei também que eles sabem coisas que eu não sei e que juntos nós poderemos progredir. Cada estágio é então concebido como um grupo de reflexão e de proposições, reagrupando os protagonistas do trabalho (os estagiários) e os "especialistas" (os formadores). Cada um aporta uma parte dos saberes e experiências necessárias para uma visão ampla do problema evocado: o objeto do estágio. Trata-se de uma preocupação de que o mundo do trabalho carece, uma demanda social, que convoca uma pluridisciplinaridade de olhares e de abordagens plurais. É o que em Ergologia nós chamamos de processo socrático de duplo sentido. Para um ergólogo ensinar é desde o início compartilhar/repartir.

Para a Ergologia, colocamos em marcha um saber pessoal, que é o resultado de nossa história individual, sempre singular, temos dito, adquirida em nossa própria experiência profissional e em outras (social, familiar, cultural, esportiva etc.) e que reenvia a nossos valores, nossa educação, ou seja, à nossa personalidade.

É esse saber - que é um verdadeiro saber - que nós chamamos: o saber investido. Para a Ergologia, o saber investido é complementar ao saber constituído. Para compreender toda situação de trabalho, essas duas formas de saberes são indispensáveis. Eles constituem duas faces de toda atividade de trabalho, sua unidade dialética.

No começo, certos estagiários ficam um pouco desconcertados por essa forma incomum. É preciso compreendê-los. Eles vieram para consumir um saber e não para produzir conhecimentos. Mas rapidamente todos se sentem incluídos, porque é o seu trabalho que está em questão e isso não pode deixá-los indiferentes.

Mas não é somente no Departamento de Ergologia que temos ideias e que nós as experimentamos. Há quinze anos, na região $\mathrm{PACA}^{5}$ e em empresas de construção civil, colocamos em prática o que chamamos de formadores em rotação, no sentido que são eles que ficam em torno do estagiário, ou formadores no local de trabalho.

Cadernos - Como funciona?

Pierre Trinquet - Ao invés de os estagiários irem até ao formador, é o formador que vem até o local de trabalho do estagiário e concebe a formação a partir de seu programa, de seus objetivos assinalados pelo solicitador e as condições de trabalho que ele encontra. Dizendo de outro modo, ele parte da realidade do trabalho e, em função de seus objetivos definidos, organiza sua formação.

A questão que se coloca na ergoformação é a seguinte: como fazer para colocar no coração da formação profissional a atividade real dos trabalhadores e utilizar seus saberes investidos? E por que fazer isso? Existem métodos para fazer isso funcionar, mas não se trata de um cardápio com receitas prontas que possam ser aplicadas a qualquer situação. Trata-se sim, de alguns conhecimentos gerais que podem ser

5 Provence, Alpes, Côte D'Azur, região do sul da França onde situa-se a Université de Provence. 
aplicados a cada situação particular. É, antes de tudo, uma questão de postura, de posicionamento do formador. Não se trata de técnicas precisas, de um método pronto. Não existem soluções milagrosas.

Nós nos inspiramos e adaptamos a organização concebida por nossos "grupos de encontros sobre o trabalho". É isso que, pessoalmente, esforço-me para praticar quando intervenho na empresa.

Cadernos - Mas o que caracteriza e diferencia essas duas formas de saberes - o saber constituído e o saber investido?

Pierre Trinquet - Vejamos primeiro o que nós chamamos de saber constituído, porque é mais simples de explicar. É o que todo mundo chama de "o saber", sem adjetivos ou, dito de outra maneira: o saber acadêmico. Ou seja, tudo que é conhecido, formalizado nos ensinos, nos livros, nos programas de computador, nas normas técnicas, organizacionais, econômicas etc.

Mas, para nós, ergólogos, esse tipo de saber, por mais importante e primordial que seja, não pode, sozinho, explicar o que se passa no trabalho tal qual ele é realizado aqui e agora. Ele é suficiente para explicar tal qual ele é prescrito, a princípio, mas não para explicar o que é realizado in fine. Uma outra forma de saber é colocada para preencher e gerir a distância entre o trabalho prescrito e o trabalho real. É esse saber que nós chamamos de "saber investido".

Cadernos - A Ergologia atribui especial importância a esse saber. O que o caracteriza?

Pierre Trinquet - É esse o saber adquirido em todas atividades ou experiências. Mas, uma vez dito isso, não se disse grande coisa!

É necessário ainda precisar: de que tipo de saber se trata? Trata-se de um verdadeiro saber? Como ele se elabora, se constrói? A que serve e pode servir? Como fazê-lo emergir, utilizá-lo? Que diferenças tem com relação ao saber constituído? São eles complementares ou concorrentes? Pode-se associá-los?

Eu certamente não responderei a todas essas questões, vastas demais e que levariam muito tempo. Simplesmente eu desejaria chamar a atenção para a importância de tudo isso e, em seguida, que cada um de nós (se convencidos), possa continuar sua busca e acrescentar sua própria contribuição.

De início, digamos que nós o chamamos investido porque ele remete à especificidade da competência adquirida na experiência da gestão de toda atividade de trabalho. E essa experiência é investida nessa situação única e histórica. Ela não é nem formalizada nem escrita em lugar nenhum. Essa experiência é localizada no intelecto e/ou no corpo, no corpo-si, diria Yves Schwartz, isto é, no corpo e no espírito (ou na alma) ao mesmo tempo, sem que haja necessidade de atribuir a este último termo qualquer conotação religiosa. Nós nos situamos, aqui, no domínio do material e do ideal.

Por outro lado, o saber acadêmico, formal, é desinvestido, ou seja, ele pode ser definido e religado com outros conceitos, independentemente das situações particulares. Ele é geral e generalizável! Ele é constituído ao exterior de todas as situações precisas.

Cadernos - Na processo formativo que o senhor nomeia como ergoformação, o saber investido ocupa um lugar central...

Pierre Trinquet - A questão que é colocada, em ergofomação, é: "como fazer, em uma formação profissional, para se servir do saber dos assalariados que se devem formar?". É esta mesma questão que se coloca quando intervimos em ergoprevenção, em ergoadministração, em ergoeconomia, em ergocomunicação etc. Há, pois, um método a colocar ali e a fazer funcionar. Esse método se ancora nos conceitos e princípios ergológicos e os torna vivos. Hoje, eu assinalo somente três que, segundo meu ponto de vista, são os mais importantes:

1) É necessário colocar no centro de nossas preocupações a atividade de trabalho. Compreender e admitir que o trabalho não é apenas uma sequência de gestos ou de ações mecânicas, programadas antecipadamente por outros. Trabalhar não é aplicar, mas é gerir as variabilidades do aqui e agora.

É por isso que, como falei, quando eu pessoalmente intervenho junto a assalariados em formação, desde o começo eu digo para eles: "Eu sei coisas que vocês não sabem. É por isso que eu estou aqui. Mas eu sei também, que, sobre seu trabalho ou, mais exatamente, sobre sua atividade de trabalho, vocês sabem coisas que eu não sei e que eu não posso saber se vocês não me disserem. E, se vocês quiserem progredir, será necessário que nós cooperemos. De outra forma, eu não seria, senão, um 'vendedor de sopa', que venho vender para você uma mercadoria que 'serve pra tudo'. Ora, isso não poderia ser eficaz porque vocês estão todos em situações de trabalho diferentes". 
Eu intervenho frequentemente para formá-los em saúde/segurança. Mas, às vezes, é junto a cozinheiros de centros de férias, às vezes junto ao pessoal de entretenimento, também em centros de férias, outras vezes, junto a soldadores de uma oficina, em outra junto a trabalhadores das docas do porto de Marseille etc. Então, claro, a regulamentação é a mesma para todos, as regras de segurança também. Mas o que lhes interessa não é conhecer generalidades, mas saber como eles vão fazer para trabalhar em segurança. Senão, eu jogaria as generalidades e em seguida continuaria sendo necessário que eles se virassem com isso. Isso não me parece sério.

É necessário reconhecer que é o momento mais delicado de cada formação. Todo o resto depende disso. Segundo minha experiência, eu posso afirmar que eles jogam o jogo. Por que? Porque é sua própria atividade que está em questão. E todo assalariado adora falar do que faz, sobretudo se nós os escutamos com atenção e se nós utilizamos o que eles dizem. E sobre este ponto, é necessário estar muito atento pois eles não devem se sentir enganados nem manipulados. É preciso ser franco!

2) É preciso construir uma estrutura que vá lhes permitir exprimirem-se e produzir. Ou, mais exatamente, adaptar essa estrutura, porque não se encontra jamais a mesma situação. Atenção, não se trata de grupos de discussão, mas de produção de saberes e de açães, o que não é a mesma coisa. $O$ objetivo do formador não é recolher informações que ele vai produzir para tratar em seguida. Seu objetivo é facilitar aos estagiários a possibilidade de adquirir um saber novo sobre sua atividade e conhecimentos para agir em segurança.

Eu utilizo, então, o que a Ergologia chama de "grupos de encontros de trabalho". Trata-se de cruzar condições para que questões surjam tanto do formador, quanto dos estagiários e que coletivamente nós procuremos as respostas apropriadas. Nós chamamos isso "processo socrático de duplo sentido". Ou seja, processos nos quais não haja apenas Sócrates (aquele que supostamente sabe, postura que Sócrates recusava, aliás), que coloca questões às quais os estagiários (aqueles que estariam na ignorância e que buscam um saber) devem responder, mas em que os estagiários também coloquem questões a Sócrates. É juntos que nós buscamos as respostas apropriadas. À primeira vista, isso pode parecer um pouco difícil de compreender, mas eu asseguro que, com um mínimo de conhecimentos ergológicos, consegue-se muito bem. É antes de tudo um problema de posicionamento, de atitude da parte do formador. É necessário aceitar um certo "desconforto intelectual", que é um conceito chave da Ergologia. Diz respeito a admitir e aceitar que não sabemos tudo e que não poderemos jamais saber tudo quando se trata de agir sobre e com humanos.

3) Terceiro e último princípio fundamental: "ir a campo, nos lugares onde ocorre o trabalho". Como falei, não podemos compreender o trabalho e agir sobre ele ficando sempre dentro de uma sala de aula. É preciso ir, com os estagiários, falar do trabalho, nos lugares do trabalho. De acordo com minha experiência, eu asseguro que é inacreditável tudo que nós descobrimos e que nós podemos entrever depois, na sala de aula. Além do mais, os estagiários ficam felizes e descontraídos, eles estão em casa. E lá eles falam com mais prazer, eles mostram e refazem na sua frente seus gestos e suas atitudes de trabalho. E, acreditem, isso é muito instrutivo.

Cadernos - Em sua tese de doutorado em Sociologia, publicada pelas Presses Universitaires de France (PUF) em 1996, sob o título Dominar os riscos no trabalho, o senhor defende que, no que diz respeito à prevenção de riscos no trabalho na França, há um "paradoxo com dupla entrada". Poderia nos dizer qual é esse paradoxo e se ele se apresenta ainda hoje?

Pierre Trinquet -Para minha tese, realizei uma pesquisa para o ministério da construção, cujo objetivo foi compreender por que, apesar de todo progresso, tanto em nível da regulamentação, da técnica, da organização do trabalho, havia sempre tantos desgastes das pessoas no trabalho. Essa pesquisa foi publicada pelas PUF, em 1996, com o título Maitriser les risques du travail ${ }^{6}$. Nessa pequisa, deparei-me com o que eu chamei de "um paradoxo com dupla entrada". Por um lado nós temos, na França, um importante e dinâmico dispositivo de prevenção, tanto em nível da regulamentação quanto das estruturas que estão colocadas. Por outro lado, um consenso do conjunto de forças sociais para que haja o mínimo possível de desgastes no trabalho. Entretanto, tudo isso é de uma ineficácia decepcionante em relação ao investimento tanto financeiro, quanto humano. Por que? Há falhas conceituais de nossa antiga regulamentação.

Para ir direto ao assunto, eu resumo e vou ao essencial: a) Ela era inspirada demais no taylorismofordismo e não levava em conta a realidade do trabalho, mas somente o trabalho prescrito. A gestão das

6 "Dominar os riscos do trabalho". A obra nunca foi traduzida para o português. 
distâncias entre o prescrito e o real - causa essencial dos desgastes - foi deixada aos assalariados, sem que eles tivessem nem os meios nem o tempo, pois se supunha que não deveria haver distância entre o trabalho tal como ele foi prescrito e como ele deveria ser realizado. Ora, sabemos agora que essa distância é incontornável; b) Ela ignorava totalmente o saber da experiência adquirida pelos atores ao longo de sua vida profissional. A prevenção era um negócio apenas de especialista e do expert. Isso está longe de ser suficiente, o que gera as inconveniências e as decepções.

Cadernos - Você diz que, em se tratando de situações de trabalho, especificamente a prevenção de riscos no trabalho, existem, em geral, três pontos de vista diferentes, em que os defensores de cada um deles tentam colocar o seu com o status de melhor que os outros, o que gera tensão frequente. Quais seriam esses três pontos de vista?

Pierre Trinquet - a) $\mathrm{O}$ referencial do prescrito legislativo e regulamentar, ou prescrito externo, ou seja, o registro da norma regulamentar (as regras); b) $\mathrm{O}$ referencial do prescrito organizacional ou prescrito da empresa, ou seja, o registro da norma dos imperativos financeiros, técnicos e organizacionais (as escolhas); c) O registro do real, ou o que se faz; o referencial da atividade, ou seja, o registro da ação e da transgressão necessária que constitui o que os ergonomistas chamam "a gestão da distância entre o trabalho prescrito e o trabalho real".

Para resumir, essa pesquisa me mostrou que nas práticas do trabalho concreto, tal como eu pude observar, as decisões que são tomadas efetivamente (regulamentação, procedimentos, técnicas, as organizações do trabalho, mas também as ações de prevenção ou de assunção de riscos) enviam a três tipos de modelos de referências diferentes (implícitas ou explícitas), que eu chamei de "referenciais", e que são frequentemente opostos. Esses referenciais são determinados e consecutivos às diferentes funções e responsabilidades próprias dos atores. Entretanto, esses três tipos de referenciais são complementares entre eles, pois as falhas de um são os pontos fortes dos outros. Mas cada um, convencido da predominância de seu ponto de vista, tenta se impor aos outros. Nós cremos que é possível reduzir essas oposições explicitando e confrontando os modelos teóricos subjacentes às representações - convicções dos diferentes atores da prevenção.

Cadernos - Atualmente, o que dificulta tanto esse diálogo?

Pierre Trinquet - Entendo que, principalmente, são dois os motivos:

a) Em primeiro lugar, cada um desses referenciais obedece a lógicas específicas e a objetivos pertinentes, incontornáveis e indispensáveis, mas que são negligenciados e, além do mais, ignorados pelos demais. Por que? Porque eles não fazem parte de suas próprias preocupações primeiras. O que reforça em cada um a vontade de se afirmar, além de impor e de considerar as preocupações dos outros como fúteis e sem lugar, exigentes demais, inúteis e por vezes perigosas. $\mathrm{O}$ que não cria as melhores condições para um diálogo construtivo.

Entretanto, o que aparece a partir de uma visão exterior e não implicada é que cada referencial tem pontos fortes e pontos fracos, eles são perfeitamente complementares. Com efeito, os pontos fracos de uns se mostram como os pontos fortes do outro e, por vezes, dos dois outros.

Para o primeiro - o referencial do prescrito legislativo e regulamentar, ou prescrito externo, ou seja, o registro da norma regulamentar - que depende do Estado, ele é a garantia e o fundamento da unidade da sociedade e cuja missão é "governar segundo a razão, em uma sociedade de cidadãos". Prioriza o político, o social, o nacional, traduzido sob a forma de leis, regulamentos e regras. É próprio de uma sociedade de direito e indispensável para nos garantir contra o arbítrio do mais forte. Mas isso se concretiza a partir de uma visão frequentemente teórica e distante da realidade do trabalho concreto. $\mathrm{O}$ que não é o caso dos outros referenciais.

Para o segundo - o referencial do prescrito organizacional ou prescrito da empresa, ou seja, o registro da norma dos imperativos financeiros, técnicos e organizacional - organizador e decisor do trabalho na empresa, a prioridade é dada ao econômico, à técnica, em função do trabalho a realizar nas condições financeiras frequentemente restritas como a concorrência obriga. Ali, o todo é traduzido sob a forma de regras, de procedimentos, de organização da produção e de ordens hierárquica, entretanto, com a preocupação do respeito às leis. O que não é fácil, em relação à suas prescrições de organização do trabalho que resultam, frequentemente, de exigências econômicas e as obrigam a fazer escolhas além dos impasses, com consequências frequentemente pesadas. Mesmo se, às vezes, pela minha experiência, podemos ter a 
impressão de que as exigências econômicas são um pretexto invocado para esconder carências administrativas. Felizmente existem leis, regulamentos e controles!

Enfim, para o último - o registro do real, ou o que se faz - o referencial da atividade, ou seja, o registro da ação e da transgressão necessária que constitui o que os ergonomistas chamam "a gestão da distância entre o trabalho prescrito e o trabalho real". É como diz com precisão Yves Schwartz, um "lugar de renormalização, de reavaliações, de retratamento de normas e valores enraizados nas gestões da atividade, com um forte envolvimento local, pouco ou nada formalizados”. Isto é, um lugar onde a prioridade é dada às necessidades e imperativos da produção concreta, em uma situação dada, traduzida sob a forma de ações em tempo real, mas com uma preocupação de segurança, que para ser constante não é menos variável de um indivíduo a outro, de um momento a outro e frequentemente com uma visão do risco corrido muito distante de uma concepção regulamentar que é frequentemente julgada mais exigente ou que traga mais segurança.

Felizmente, o essencial de sua prevenção é pensado e organizado no começo pelo técnicos. Mesmo que isso demande deixar uma certa margem de manobra para os assalariados se adaptarem às variabilidades inerentes a toda atividade de trabalho. Mas ainda seria necessário admitir e lhes dar meios adequados.

b) Em segundo lugar, porque não funciona eficazmente nenhum lugar de confrontação e de tentativa de tornar coerentes as zonas de conhecimento comuns. Salvo, no seio das empresas, entre os referenciais do prescrito organizacional e aquele da atividade, pelo intermédio das relações de trabalho entre os prescritores e os executantes, em um retorno da experiência. Mas também, na França, pelos intermédios dos CHSCT (Comitês de Higiene, Segurança e Condições de Trabalho), quando eles existem e funcionam corretamente. Essa instância representativa do pessoal é a única abertura institucionalizada na empresa para o mundo exterior e o lugar onde os três referenciais são reunidos.

Cadernos - Mas, então, apesar das dificuldades, tem havido concretamente diálogo entre esses três referenciais...

Pierre Trinquet - Atualmente, as ligações entre estes três referenciais não funcionam sob a forma de trocas de pontos de vista organizados ou de confrontações. Elas funcionam como imposição regulamentos, regras, ordens e seus corolários: medidas de evitamento, além de desobediência - ou sob a forma de coleta de informações, de dados novos e de evoluções dos conteúdos dos outros referenciais (frequentemente de forma fortuita porque não são organizadas sistematicamente). E cada um fechado em seu próprio referencial. O que os faz evoluir, mas lentamente e em descompasso com a realidade que vai cada vez mais rápida. E essa aceleração, muito característica de nossa época, é cheia de consequências. É tudo isso que está, para dizer o essencial, na origem das distâncias constatadas entre os referenciais.

Cadernos - Frente a essas dificuldades, qual tem sido a postura teórico-metodológica do grupo de pesquisadores do qual o senhor participa?

Pierre Trinquet - Para dominar um pouco melhor essa dialética obrigatória entre os saberes constituído e investido, seria conveniente conceber lugares de encontro ou espaços de cooperação, cujo objetivo essencial seria a organização de confrontação de pontos de vista e de trocas de informações relativas à atividade real, com o objetivo de reduzir essas incompreensões entre os diferentes registros da atividade industriosa. E isso, utilizando de caminhos mais eficazes do que aqueles que existem atualmente e que são longos demais, estreitos demais e por demais fechados à passagem dos saberes práticos (de prudência) dos operadores. A prevenção se elaboraria assim a partir disso que G. de Terssac e C. Chabaud chamam um "referencial comum e operativo", operando pontes e retroações entre esses três níveis diferentes da polaridade dos registros.

Mas isso supõe uma abertura a uma maneira ergológica de agir com a ajuda de saberes e de métodos atualmente disponíveis, no interior da qual não haveria imposição de hierarquia de valores nem de lógica. A abordagem seria necessariamente participativa, a experiência do operador tendo o mesmo status que o conhecimento do expert. Não sob a forma de uma concorrência ou de oposição, mas em complementaridade, em enriquecimento mútuo.

Cadernos - Por isso o senhor utiliza "grupos de encontro de trabalho"? Qual é seu papel na prevenção dos riscos no trabalho, que o senhor chama de "ergoprevenção"?

Pierre Trinquet - Para a Ergologia, todas as questões que dizem respeito ao trabalho - saúde/segurança, formação, administração, economia etc. - não podem ser abordadas com alguma pertinência apenas 
pelos experts, quaisquer que sejam eles e quaisquer que sejam suas competências e sua boa vontade. É complexo demais! Somente um coletivo que reúne o máximo de representantes possível desses três referenciais permitirá a abordagem. Mas ainda é necessário que esse coletivo respeite certas condições de organização e de funcionamento. Essas condições remetem ao conjunto dos conceitos e à metodologia ergológica.

Para conseguir isso, os "grupos de encontro de trabalho" se constituem em um método que permite alcançar esses objetivos. Mas isso não é certamente a única coisa a fazer, porque é a filosofia geral do encaminhamento das questões que está em causa e não as soluções, que podem variar de uma situação a outra. Pressupõe um coletivo de pessoas envolvidas na situação, inclusive os trabalhadores, uma abordagem pluridisciplinar e uma formação ergológica.

A segurança do trabalho é a expressão de uma relação social. E essa relação social atual, vertical demais, hierarquizada demais, não permite responder eficazmente à complexidade intrínseca ao trabalho humano. É no quadro de uma redefinição dessa relação social que é necessário conceber toda problemática, se desejamos nos orientar para soluções confiáveis.

Cadernos - Muito obrigado.

Pierre Trinquet - Foi um prazer. 